\title{
Recent development of smart traffic lights
}

\author{
A'isya Nur Aulia Yusuf, Ajib Setyo Arifin, Fitri Yuli Zulkifli
}

Department of Electrical Engineering, Universitas Indonesia, Indonesia

\section{Article Info}

Article history:

Received Sep 26, 2020

Revised Nov 3, 2020

Accepted Dec 14, 2020

\section{Keywords:}

Adaptive traffic light

Intelligent transportation

system

Machine learning

Smart city

Smart traffic light

\section{Corresponding Author:}

A'isya Nur Aulia Yusuf

Department of Electrical Engineering

Universitas Indonesia

Kukusan, Beji, Kota Depok, Jawa Barat, Indonesia 16425

Email: aisya.nur@ui.ac.id

\begin{abstract}
Increased traffic flow causes congestion, especially in large cities. Even though congestion is not unusual, traffic jams still result in very high economic and social losses. Several factors cause congestion, one of which is traffic lights. Therefore, a mechanism is needed so that traffic lights can intelligently and adaptively manage signal time allocation according to traffic flow conditions. A traffic light with this type of mechanism is known as a smart traffic light. Smart traffic light cycle settings can be grouped based on the traffic density, scenarios for emergency vehicles, and the interests of pedestrians. This paper analyzes the methods and technologies used in the development of smart traffic light technology from the perspective of these three situations as well as the development of smart traffic light technology in the future.
\end{abstract}

This is an open access article under the CC BY-SA license.

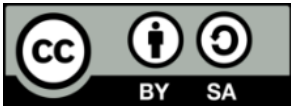

\section{INTRODUCTION}

Increases in traffic flow, especially in large cities, cause the problem of congestion. In addition to the traffic density, the population, economy, and infrastructure influence congestion. Even though congestion is not unusual, traffic jams still cause very high losses both economically and socially. Based on research conducted by INRIX in 2018 [1], in Istanbul (Turkey) and Moscow (Russia), the time losses of motorists due to traffic jams reached 210 and 157 hours, respectively. In Boston (United States), congestion caused 164 hours to be lost, with losses per driver reaching \$2,291 and city damages as high as \$4.1 billion. In Indonesia alone, in 2017 [2], congestion caused an average of 56 hours of time loss. Jakarta, in the same year, became the 12th most congested city in the world, with a loss of 63 hours lost due to traffic. Table 1 shows the impact of congestion in terms of time loss. Table 2 shows the economic damage caused by congestion.

In addition to the time and economic impacts, congestion negatively impacts motorists who are trapped in traffic. From the psychological perspective, [3] states that congestion can cause stress and aggressive behaviour. According to [4], several factors cause congestion, such as road narrowing, traffic density, and traffic lights. The fixed cycle method, which is still used in most traffic lights, is currently considered inefficient because it increases traffic density and congestion, especially on roads that have high traffic flow volumes [5]. Therefore, a mechanism is needed so that traffic lights can intelligently and adaptively manage signal time allocation according to traffic flow conditions. This type of mechanism gave rise to the new term "smart traffic light".

In general, the development of smart traffic light technology has been discussed in research [5-8]. However, the previous paper has not thoroughly discussed the technology, both in terms of hardware and software, as well as further development of smart traffic light. Research related to smart traffic lights has 
produced traffic lights that can adapt to certain traffic situations. Smart traffic light cycle settings can be grouped based on the traffic density, scenarios for emergency vehicles, and the interests of the pedestrian. This paper analyzes the methods and technologies used in the development of smart traffic light technology from the perspectives of these three situations. As novelties of this paper are comprehensive review and prediction of the development of smart traffic light technology in the future. The composition of this paper is: chapter 2 discusses the classification of current smart traffic light technology, chapter 3 describes the recent developments of smart traffic lights, and the conclusions are presented in chapter 4.

Table 1. Losses in large cities due to congestion [2]

\begin{tabular}{ccccccc}
\hline Rank & City & Country & Continent & $\begin{array}{c}\text { Peak Hours Spent in } \\
\text { Congestion }\end{array}$ & $\begin{array}{c}\text { Inrix Congestion } \\
\text { Index }\end{array}$ & $\begin{array}{c}\text { Average Congestion } \\
\text { Rate }\end{array}$ \\
\hline 1 & Los Angeles; CA & USA & North America & 102 & 18.3 & $12 \%$ \\
11 & Bangkok & Thailand & Asia & 64 & 12.5 & $23 \%$ \\
12 & Jakarta & Indonesia & Asia & 63 & 13.4 & 10.8 \\
13 & Washington; DC & USA & North America & 63 & 10.6 & $11 \%$ \\
24 & Rio de Janeiro & Brazil & South America & 51 & 9.1 & $15 \%$ \\
25 & Munich & Germany & Europe & 51 & & $16 \%$ \\
\hline
\end{tabular}

Table 2. Economic losses due to congestion [1]

\begin{tabular}{|c|c|c|c|c|c|c|}
\hline Urban Area & $\begin{array}{l}\text { Hours Lost in } \\
\text { Congestion } \\
\text { (Rank 2018) }\end{array}$ & $\begin{array}{l}\text { Year Over } \\
\text { Year } \\
\text { Change }\end{array}$ & $\begin{array}{c}\text { Inner City Last- } \\
\text { mile Travel } \\
\text { Time (minutes) }\end{array}$ & $\begin{array}{c}\text { Inner City } \\
\text { Last-mile } \\
\text { Speed (mph) }\end{array}$ & $\begin{array}{c}\text { Cost of } \\
\text { Congestion } \\
\text { (per driver) }\end{array}$ & $\begin{array}{c}\text { Cost of } \\
\text { Congestion } \\
\text { (per city) }\end{array}$ \\
\hline Boston, MA & $164(1)$ & $-10 \%$ & 6 & 11 & $\$ 2,291$ & $\$ 4.1 \mathrm{~B}$ \\
\hline Washington, DC & $155(2)$ & $-3 \%$ & 5 & 11 & $\$ 2,161$ & $\$ 4.6 \mathrm{~B}$ \\
\hline Chicago, IL & $138(4)$ & $4 \%$ & 5 & 12 & $\$ 1,920$ & $\$ 6.2 \mathrm{~B}$ \\
\hline London & $227(1)$ & $1 \%$ & 8 & 7 & $£ 1,680$ & £ 4.9B \\
\hline Birmingham & 134 (12) & $-4 \%$ & 5 & 12 & $£ 994$ & £ $388.7 \mathrm{M}$ \\
\hline Glasgow & $99(16)$ & $4 \%$ & 5 & 13 & $£ 736$ & $£ 320.4 \mathrm{M}$ \\
\hline
\end{tabular}

\section{RESEARCH METHOD}

A traffic control mechanism was first attempted in Toledo, Ohio, in 1908, involving semaphore signals from a tower in the middle of an intersection controlled by the police inside. The adoption of traffic light technology began after Henry Ford introduced the model T in 1908, which began being mass-produced in 1913 [9]. In 1920, William Potts created the first four-way, three-color traffic lights by adding an amber "caution" light, whereas previous traffic lights had included only two signal lights, red and green. The addition was made to increase the safety of the driving process. This traffic light design became standard in the mid-1930s and was installed in Detroit, Michigan [10]. The development of traffic lights has continued through the application of new technologies or combinations of existing technologies. Figure 1 shows the classification of the development of the traffic light technology that exists today.

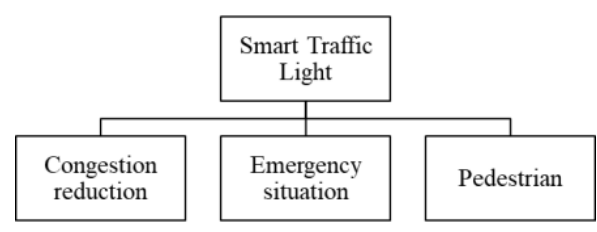

Figure 1. Smart traffic light classification

In general, research on traffic lights focuses more on setting signal scheduling in accordance with the main motivations of traffic lights. Based on their motivation, smart traffic lights can be divided into traffic lights to reduce congestion and give priority to vehicles in emergency situations or traffic lights whose scheduling adjusts to the presence and number of pedestrians. Studies [11-44] focus on scheduling traffic lights to reduce congestion. With this motivation, traffic lights detect the number or length of vehicle queues in one lane and compare this value to that of other lanes. A longer green light will be given for lanes with greater numbers of vehicles or queue lengths. Studies [45-52] focus on scheduling traffic lights for emergency situations. Basically, with this motivation, traffic lights detect approaching emergency vehicles and assign a green light to the lane that the approaching emergency vehicle is in. This mechanism ensures 
that emergency vehicles always have the green lights every time they pass through a traffic light so that emergency vehicles can reach their destination as soon as possible. In studies [53-56], the motivation of the traffic light design is to detect pedestrians and let them cross the road first. A detailed explanation of each study is presented in the following chapters.

\section{RESULTS AND DISCUSSION}

Based on their motivation, smart traffic lights can be divided into traffic lights to reduce congestion and give priority to vehicles in emergency situations or traffic lights whose scheduling adjusts to the presence and number of pedestrians.

\subsection{Smart traffic lights for congestion reduction}

In [11], an emergency traffic control system for an intersection in the event of an accident, with deadlock recovery, livelock prevention, and conflict resolution, is designed based on Petri nets (PNs). A PN is a model for simulating and analyzing complex discrete event dynamic systems. In [12] determines the best location for installing sensor networks in traffic networks. In this study, three types of agents are designed so that the minimum travel time can be achieved: a traffic light management agent, a traffic detection agent, and a traffic light control agent at an intersection. In [13] uses a wireless sensor network (WSN) that is implemented at a crossroads, and these sensors make decisions about traffic movements to minimize the waiting times and average queue lengths. The algorithm proposed in this system optimizes traffic light scheduling without changing the order of the current light cycles so that road users are not confused.

In [14], a system that is able to recognize traffic lights on a smartphone platform is created. The proposed system is also able to recognize the traffic light cycle. In [15] proposes a system consisting of three agents, namely, traffic light management agents (TLAgents), traffic jam detection agents (TJamAgents) and agents that control traffic lights at intersections (IntersectionAgents). A TLAgent is placed at each traffic light to regulate the changes in the light signals. TJamAgents are placed in vehicles and sensors installed in several places and receive traffic information. A IntersectionAgent is a traffic light communication system at a particular intersection that receives information from the nearest TJamAgent and determines the traffic light cycle based on that information. In [16] utilizes RFID technology to detect traffic jams. The traffic light cycle is dynamically regulated based on traffic density to minimize congestion with the help of an internet of things (IoT) sensor. Each vehicle has a passive RFID tag installed, and the sensor records the number of vehicles passing through to the next sensor. In [17] proposes a pheromone-based traffic management framework to reduce congestion by combining dynamic vehicle rerouting strategies and traffic light control. Each vehicle pheromone traffic deposit and pheromone intention (representing the current and future traffic densities) are recorded during a trip. If congestion occurs, the framework adopts a proactive vehicle rerouting strategy, where vehicles that need to be rerouted are selected and given an alternative route before they enter a jammed road. In [18] evaluates two scheduling algorithms, namely, the earliest deadline first (EDF) and fixed priority (FP) algorithms. In the FP algorithm, vehicles are grouped into four classes. The lane with the highest priority vehicle is served first. In the EDF algorithm, vehicles are prioritized based on deadlines to destinations. With this algorithm, the number of stops, average delays and prioritized vehicle travel times are significantly reduced. The EDF algorithm yields better performance than FP. In [19] proposes an image processing-based traffic control system using MATLAB code that changes the traffic light signal time by considering the traffic density. The system aims to reduce waiting times on empty roads. The image in each lane is obtained using a webcam, and the number of vehicles on the road and the traffic density are calculated by applying the suitable MATLAB function. The duration of the green light is determined based on the density of the traffic duration, where a longer time is given for denser roads.

In [20] devises a two-level strategy at the intersection to prevent congestion caused by accidents. Level one is used to stop a vehicle from driving in a certain direction, and level two is used to give a warning that recommends not driving in a certain direction. In [21] proposes an artificial bee colony (ABC) algorithm to minimize the average waiting time (AWT) at an intersection based on the dynamic traffic load input. This algorithm is inspired by honeybee swarm behaviour and can optimize the waiting time by $98.43 \%$ for a simulation duration of 1800 seconds. In [22] uses traffic congestion data from Google's API to design adaptive traffic lights that can reduce traffic congestion by detecting congestion from the point of departure to the nearest traffic light. One advantage of this method is that it does not have high infrastructure installation costs (such as those for the installation of sensor networks). Information can be delivered with an average delay of 1.5 seconds (maximum of 3 seconds). In [23] sets traffic lights so that vehicles do not stop when traffic conditions are low using LaNPro (a smart traffic light module specifically for quiet streets/intersections). In [24] proposes a two-way traffic-light-to-vehicle communication (TLVC) scheduling scheme to reduce fuel consumption and $\mathrm{CO} 2$ emissions by ensuring that large vehicles can directly cross 
traffic lights without stopping. Heavy-duty vehicles are given priority to cross the traffic light first. The simulation results show that the green light hit rate for all vehicles, especially vehicles with heavy loads, increases significantly. In [25] uses a WSN to collect road traffic data in real-time, a fuzzy logic controller (FLC) for decision making (which path to give the green light to first), and a routing algorithm that dynamically gives a green light based on data from the FLC. In [26] proposes a dynamic routing strategy that constantly provides motorists with travel time updates and considers adaptive signal control for efficient routing in the actual transport network. Routing is used to reduce the queue length and average waiting time and increase the average speed in the network. In [27] uses the adaptive neuro-fuzzy inference system (ANFIS) method to process road density and road width data to determine the duration of a given green light. The road density is calculated based on the video taken by the system and processed using the connected component labeling (CCL) method. CCL image results are compared with the image condition of an empty road (without a vehicle) to obtain the vehicle density percentage. Road condition data (in the form of video footage) are collected, and road images are taken when there are no vehicles (clear road conditions). When the object in the test image has been obtained, the road density is calculated by comparison with the empty road image that was previously obtained. Data on the road density and line width are the ANFIS inputs for determining the duration of a given green light. In [28] proposes a pretimed system to accommodate traffic variations. The system determines the traffic density from the intensity histogram standard deviation of the image representing the vehicle detection area of a lane and modifies the green time of each intersection. The system controls the flow of vehicles based on signal-timing plans and determines the traffic density by detecting all objects in the vehicle detection area in each lane with four wireless IP cameras and then modifying the current green time of a lane. Each camera captures the entire vehicle waiting area, but the program detects only the vehicles in the vehicle detection area. The traffic density is determined by calculating the intensity histogram in the entire region of interest (ROI). The system calculates the standard deviation of the histogram. If the value is smaller than the low threshold, the system concludes that traffic density is low, and green time is shortened. If the value is higher than the high threshold, the system concludes that the traffic density is high, and the green time is extended.

In [29] builds two kinds of reinforcement learning algorithms, namely, deep policy-gradient (PG) and value-function-based agents, that can predict the best possible traffic signal for traffic intersections. The adaptive traffic light control agent receives a snapshot of the current graphical traffic simulator and generates a control signal. PG-based agents map their observations directly to the control signal, while value-functionbased agents first estimate the values for all legal control signals and then choose the optimal control action with the highest value. In [31] models the traffic signal controller using an actor-critic reinforcement learning advantage algorithm (A3C) with various state representations to determine differences in performance. The parameters studied include the vehicle density, traffic flow, queues, location, and speed together with the current traffic phase, cycle length and duration of red lights. In [32] introduces a new approach based on a modified round-robin scheduling algorithm based on genetic algorithm techniques that optimize the timing efficiency of signaled intersections. In order to evaluate the cost function and check if the global optimum has been reached, this technique uses initial timing patterns to produce new offspring (in terms of length of delay). The modifications implemented in the traditional normal round-robin scheduling algorithm are based on NOR logic gates. When two vertically connected lines do not have vehicle activity, instead of the traffic system giving them a green light, the system will give a green light to another lane that has at least one vehicle that will cross the intersection. A set of traffic counters is applied during 3 specific periods to capture the traffic flow and delay in each crossing lane. The calculation lasts for 20 minutes in each period. In [33] proposes an automated system that can detect emergency vehicles in heavy traffic from CCTV footage using a deep convolutional neural network to communicate this information to traffic lights or to automatically navigate other vehicles to clear the roads (giving priority to emergency vehicles). This system takes road recordings from CCTV and detects emergency vehicles. Pictures are taken every second with the CCTV cameras. In each picture, each vehicle on the road is detected and the system classifies the vehicles into emergency vehicles and ordinary vehicles. If an emergency vehicle is found, the computer notifies the traffic police or the automated system to clear the road. The Yolo-V3 algorithm is used for object detection because this algorithm is fast and capable of processing 45 images per second with a computer with a good processor. In [34] detects red lights and gives vehicles and pedestrians warnings near red lights using a smartphone. A priority system for traffic lights, which weights each lane based on the number and type of vehicles which are in that lane, is implemented. In [35] proposes a system consisting of trusted authority (TA) that regulates vehicle databases and communicates with vehicles with $3 \mathrm{G} / 4 \mathrm{G}$ networks. In addition, a traffic light system is introduced that operates by exchanging information (vehicle status) between the vehicle and the traffic light controller. Based on the state of the vehicle, the traffic light determines which vehicle has priority. In [36] proposes vehicle macroscopic motion planning (VMMP) for route optimization and vehicle speed using data traffic and vehicle characteristics with vehicle connectivity (V2V, V2I, vehicle-to-cloud). The algorithm used 
to determine the vehicle routes is a genetic algorithm. In [37] proposes a data transmission communication mechanism involving three units: congestion detection, data control, and congestion control. Congestion detection is used to measure the level of the channel used to detect congestion. Data control is used to collect and filter messages (to avoid redundancy) and then to group messages into 4 clusters. Congestion control is used to determine the communication parameters (transmission range, rate). The predetermined communication parameters are sent by traffic lights to vehicles that need to stop at red lights to reduce collisions and control congestion. In [38] exploits a five-megapixel resolution CCD camera designed and used to monitor real-time traffic approaching each intersection and to measure the traffic volume of each lane and queue, transmitting real-time data parameters to the traffic light control system, such as the length of the vehicle and the average waiting time. The device will define the video frame by frame and match the route in question automatically, monitor the passage of vehicles and make decisions based on the actions of vehicles. To control traffic lights at one point, a real-time traffic indicator is linked to traffic lights. This system can also be used as a sensor for traffic guidance systems for the urban road network to provide traffic guidance input data and to monitor the overall road conditions automatically.

In [39] develops a better and dynamic traffic light control design using the fuzzy Mamdani logic method. The analysis is based on the length of the vehicle queue in each lane at the intersection, the width of each road, the number of vehicles heading to the traffic (intersection) and the vehicle speed. The duration of the green light period for each lane can be optimized based on parameters such as the length of the queue in each lane, the number of vehicles entering the queue, the vehicle speed and the width of each lane. From the parameter values, the $\mu$ value is then determined for application based on the rule calculation. Lanes with longer vehicle lines will have longer green light periods than other lanes with fewer vehicles. In [40] proposes validation strategies based on genetic algorithms and automatic generation for different traffic scenarios. Some of the parameters used for validation assessment include the number of vehicles arriving at their destination, $\mathrm{CO} 2$ emissions, $\mathrm{NOx}$, and travel time (can select certain cycles for certain traffic conditions). In [41] optimizes the traffic flow by proposing two approaches: RITCO and VITCO. With RITCO, the sensor collects road information (queue number of vehicles) and then tells the traffic lights to set the cycle based on the information. With VITCO, vehicles exchange information with each other to detect traffic jams and tell traffic lights to regulate cycles. In [42] designs a real-time traffic light optimization system to respond to sudden changes in parameters so that the traffic system can operate efficiently. The system calculates the number of vehicles in a lane and determines the scheduling of traffic lights based on that number. In [43] uses sensors and cameras to collect traffic data. These data are subsequently analyzed, with the sensor data being used to provide traffic information. If the length of the traffic queue is longer than 100 meters, the vehicles approaching the intersection will be notified. The camera data are used to view the vehicle data (license plate, type of vehicle). In [44] proposes a history-based traffic management algorithm. The traffic information of the previous year are used to predict current traffic flow. From these predictions, the cycle for green lights and red lights is then regulated.

\subsection{Smart traffic lights for emergency vehicles}

In [45] uses RFIDs to detect stolen vehicles. If a stolen vehicle crosses an intersection, an SMS is sent to the police post. Emergency vehicles are distinguished by RFID tags, and the concept of green waves (always getting a green light) is used. This mechanism does not use a camera due to weather problems (if the weather is bad, the image quality deteriorates, and the image processing is complicated). In [46] constructs an integrated system so that each vehicle can communicate. Each vehicle provides information (speed) for other vehicles. The green light duration is calculated based on the distance of the vehicle to the intersection and the estimated time of arrival. The number of vehicles is counted using a camera, and emergency vehicles are distinguished using sensors. In [47] designs an accident detecting, alerting and tracking mechanism so that an ambulance can immediately pass through an intersection as quickly as possible. The system is equipped with a patient health (vital sign) monitoring system. In [48] establishes a traffic control scheme based on PLCs. For detecting emergency vehicles and triggering emergency protocols, RFID tags are used. Under normal operating conditions, the normal signal sequence is maintained; when the emergency protocol is triggered, the state of the device is changed before an emergency vehicle reaches the intersection. The machine returns to its usual state when the emergency situation is over. In [49] designs a control system based on software defined networking (SDN) and the IoT to modify the traffic light cycle when there is an emergency with the aid of traffic cameras. The SDN controller contacts the cloud to collect traffic data and arrange the traffic light cycle based on that data. In [50] uses RFID to track the arrival of ambulances at a certain distance. The RFID data are processed by a microcontroller, which changes the light signal to green when the ambulance passes through the traffic light. GPS, which is embedded in ambulance driver mobile devices, is used to send information from mobile devices to the cloud. The mobile devices are used to authenticate the emergency and nonemergency conditions of the ambulance. In [51] suggests that a system signal the nearest traffic light 
when an ambulance approaches. RFID technology is used in this study by embedding RFID tags in ambulances. The ambulance driver activates the tag if the ambulance is under emergency conditions, and then the tag is detected by a traffic light with an RFID reader. The traffic light changes to green when the ambulance reaches a certain distance from the traffic light and remains green until the ambulance passes the traffic light.

In [52] uses RFID to control traffic signals by measuring vehicle density. RFID-based technology that can clear traffic congestion during crowded hours and provide emergency vehicles with protected lanes is proposed. The main aim of this system is to control traffic effectively and encourage movement by emergency vehicles. Emergency vehicles are marked when, at a certain distance, an RFID signal is detected. When an emergency vehicle is approaching, the traffic server notifies the Arduino at the junction. This information obtained by Arduino is then balanced by the RFID signal acquired from the RFID reader. This confirms whether or not the car is in an emergency setting. Until verified, by switching to the green light, the path for the emergency vehicle is cleared. If an emergency vehicle receives an RFID signal from Arduino, then the green lights are given for their direction. Traffic information is submitted to the server so that, using web pages, users can determine the traffic conditions.

\subsection{Smart traffic lights for pedestrians}

In [53] uses a fuzzy-based approach by applying three membership functions (low, medium, and high) for the number of pedestrians (input) and the phase of the traffic lights (output). The critical time (crossing time again is tight) and noncritical time are determined by a rule. Pedestrian crossing is prioritized, so the allocation of red light time for vehicles increases if the number of crossers increases. In [54] optimizes traffic lights so that slow pedestrians (disabled/elderly people) can cross safely and congestion is minimized. Additional green light time is allocated to pedestrians only when a slow pedestrian is detected (from the IoT device installed on the slow pedestrian). In [55] establishes a model for signal-controlled intersection simulation that can be used to test the efficacy of adaptive control in different traffic conditions, including the presence or absence of intersectional pedestrian traffic using the Monte Carlo method. The difference in the speed of the incoming traffic flow and the presence or absence of pedestrian traffic is determined by the vehicle delay, queue length, and traffic light cycles. This research creates a numerical model that represents the performance of an intersection with adaptive control to obtain the average value of the traffic light cycles that can be used, the length of the queue and the vehicle delay. In [56] proposes a road crossing system using sensors, CCTV, and illuminators to track pedestrians and illuminate them to help motorists more easily avoid dangerous situations. This system consists of six main parts, namely, a CCTV analyzer, which works closely with CCTV to track pedestrians and record crossings; boundary detectors to detect pedestrians and vehicles entering certain areas; illuminators to illuminate crossings and allow pedestrians to be seen from afar and to provide light for CCTV; control units and control centers to obtain the latest traffic conditions and send certain video recordings and operate algorithms; and emergency response centers for reporting systems to the control center in the event of an accident.

\subsection{Discussion}

The development of smart traffic light technology includes several aspects, including the process of vehicle detection, both public and emergency vehicles, the process of pedestrian detection, and the scheduling algorithm used for various specific situations. In the process of detecting vehicles or traffic congestion, technology such as cameras, wireless sensor networks, and RFID is used. To detect pedestrians at a crossing, the camera technology is often used. RFID technology is commonly used to distinguish types of vehicles. In this case, emergency vehicles are more widely given RFID to distinguish them from other vehicles. When a traffic light detects the presence of RFID in an emergency vehicle, the lane of the emergency vehicle is given priority for the green light so that the emergency vehicle can directly pass through the crossing without stopping. RFID is chosen because it has a long-distance range, does not require a line of sight, is robust to challenging environments and can track objects in real-time. Cameras are alternative technology for detecting vehicle density and the presence of pedestrians because they can describe traffic conditions with high accuracy from the results of image processing, although the level of accuracy is directly proportional to the image quality obtained. In terms of the use of algorithms for scheduling traffic lights, in general, artificial intelligence and machine learning algorithms such as fuzzy logic algorithms, genetic algorithms and neural networks are used. Each of these algorithms has advantages and disadvantages, as shown in Table 3.

Although the development of smart traffic light is able to provide convenience such as reducing travel time and stops at intersections, there is one problem that hinders the adaptation of smart traffic light, namely the costs required for signal control devices, communication networks and periodic updates to regulate systems that are able to adapt to traffic conditions. This adaptive system requires periodic traffic 
research and recalibration. For further technological developments, both in terms of industry and academic research, it is expected that smart traffic lights will be able to operate in accordance with changing traffic conditions through high-speed communication. Further development of the algorithm is required to be able to integrate position, speed and queue data received from vehicles as well as sensor and transmitter infrastructure, to make predictions and strategies to monitor, learn and respond to traffic conditions optimally. In the following years, smart traffic light is expected to become an infrastructure capable of managing traffic independently so that the human error factor in this task can be minimized.

Table 3. Comparison of algorithms used for smart traffic light scheduling

\begin{tabular}{clll}
\hline & \multicolumn{1}{c}{ Fuzzy Logic Algorithm } & \multicolumn{1}{c}{ Genetic Algorithm } & \multicolumn{1}{c}{ Neural Network } \\
\hline Advantages & $\begin{array}{l}\text { Uses simple mathematics for systems } \\
\text { that are nonlinear, is integrated and } \\
\text { complex; has high precision. }\end{array}$ & $\begin{array}{l}\text { Supports multiobjective } \\
\text { optimization; is suitable for } \\
\text { discrete problems, continuous } \\
\text { problems or both. }\end{array}$ & $\begin{array}{l}\text { Can learn from complex and } \\
\text { nonlinear relationship models; } \\
\text { has no limits on the input } \\
\text { variables. }\end{array}$ \\
Disadvantages & $\begin{array}{l}\text { Has very high computational } \\
\text { requirements for a high degree of } \\
\text { accuracy; response is not real-time; } \\
\text { limited use of input variables. }\end{array}$ & $\begin{array}{l}\text { Hequirements; takes a long } \\
\text { time. }\end{array}$ & $\begin{array}{l}\text { Requires considerable } \\
\text { computing resources; no } \\
\text { specific rules for determining } \\
\text { the network used. }\end{array}$ \\
\hline
\end{tabular}

\section{CONCLUSION}

Smart traffic light is a technology that is expected to be able to solve congestion problems. The methods and technologies used in the development of smart traffic light to reduce traffic density and detect emergency vehicles as well as pedestrian are analyzed in this paper. In the future, smart traffic light is expected to manage traffic independently to reduce the human error factor in this task.

\section{ACKNOWLEDGEMENTS}

This work is funded under the contract number NKB-3041/UN2.R3.1/HKP.05.00/2019 by the Indonesian Government Scholarship PMDSU from the Ministry of Research, Technology, and Higher Education (Kemristekdikti).

\section{REFERENCES}

[1] T. Reed and J. Kidd, "INRIX Global Traffic Scorecard," 2019. [Online]. Available: https://static.poder360.com.br/2019/02/INRIX_2018_Global_Traffic_Scorecard_Report_final_.pdf.

[2] G. Cookson, "INRIX Global Traffic Scorecard," 2018. [Online]. Available: https://www.missionline.it/wpcontent/uploads/2018/02/INRIX_2017_Traffic_Scorecard_Final.pdf

[3] D. A. Hennessy and D. L. Wiesenthal, "Traffic Congestion, Driver Stress, and Driver Aggression," Aggresive Behav., vol. 25, pp. 409-423, 1999, DOI: 10.1002/(SICI)1098-2337(1999)25:6<409::AID-AB2>3.0.CO;2-0.

[4] Jakarta Open Data, "Causes of Congestion in Jakarta in 2011," 2015. [Online]. Available: http://data.jakarta.go.id/dataset/d341296f-f5c3-4276-9cdb-b514d14673b9/resource/a4175fba-a0eb-4ced-9f668e225206a06f/download/Data-Penyebab-Kemacetan-di-Jakarta-Tahun-2011.csv. [Accessed: 27-Apr-2019].

[5] O. Avatefipour, S. Member, F. Sadry, and S. Member, "Traffic Management System Using IoT Technology - A Comparative Review," 2018 IEEE Int. Conf. Electro/Information Technol, 2018, pp. 1041-1047, doi: 10.1109/EIT.2018.8500246.

[6] M. Kabrane, S. Krit, and L. El Maimouni, "Smart Cities: Study and Comparison of Traffic Light Optimization in Modern Urban Areas Using Artificial Intelligence," Int. J. Adv. Res. Comput. Sci. Softw. Eng., vol. 8, no. 2, pp. 1018, 2018, doi:10.23956/ijarcsse.v8i2.570.

[7] R. Hawi, G. Okeyo, and M. Kimwele, "Techniques for Smart Traffic Control: An In-depth Review," Int. J. Comput. Appl. Technol. Res., vol. 4, no. 7, pp. 566-573, 2015, doi:10.7753/IJCATR0407.1014.

[8] A. H. Ahmed, "A Review of Adaptive Intelligent Traffic Control Systems," J. Res. Bus. Soc. Sci., vol. 1, no. 1, pp. 2209-7880, 2018.

[9] C. Mcshane, "The Origins And Globalization Of Traffic Control Signals," J. Urban Hist., vol. 25, no. 3, pp. 379404, 1999.

[10] The Henry Ford, "First Tri-Color, Four-Directional Traffic Signal, 1920." [Online]. Available: https://www.thehenryford.org/collections-and-research/digital-collections/artifact/227457/\#slide=gs-225140.

[11] L. Qi, M. Zhou, and W. Luan, "Emergency Traffic-Light Control System Design for Intersections Subject to Accidents," IEEE Trans. Intell. Transp. Syst., vol. 17, no. 1, pp. 1-14, 2016, doi:10.1109/TITS.2015.2466073.

[12] L. Cruz-piris, D. Rivera, S. Fernandez, and I. Marsa-maestre, "Optimized Sensor Network and Multi-Agent Decision Support for Smart Traffic Light Management," Sensors, vol. 18, no. 2, pp. 435, 2018, doi:10.3390/s18020435. 
[13] K. Zaatouri, M. H. Jeridi, and T. Ezzedine, "Adaptive Traffic Light Control System Based on WSN : Algorithm Optimization and Hardware Design," in 26th International Conference on Software, Telecommunications and Computer Networks (SoftCOM), pp. 1-6, 2018, doi:10.23919/SOFTCOM.2018.8555802.

[14] W. Liu et al., "Real-Time Traffic Light Recognition Based on Smartphone Platforms," IEEE Trans. Circuits Syst. Video Technol., vol. 27, no. 5, pp. 1118-1131, 2017, doi:10.1109/TCSVT.2016.2515338..

[15] L. Cruz-piris, D. Rivera, I. Marsa-maestre, E. De, and S. Fernandez, "Intelligent Traffic Light Management using Multi-Behavioral Agents," in Jornadas de Ingenieria Telematica, pp. 27-29, 2017, doi: 10.4995/JITEL2017.2017.7061.

[16] A. Atta, S. Abbas, and M. A. Khan et al., "An adaptive Approach : Smart Traffic Congestion Control System," J. King Saud Univ. - Comput. Inf. Sci., 2018, doi:10.1016/j.jksuci.2018.10.011.

[17] Z. Cao, S. Jiang, J. Zhang, and H. Guo, "A Unified Framework for Vehicle Rerouting and Traffic Light Control to Reduce Traffic Congestion," IEEE Trans. Intell. Transp. Syst., vol. 18, no. 7, pp. 1958-1973, July 2017, doi:10.1109/TITS.2016.2613997.

[18] A. Ahmad, R. Arshad, S. A. Mahmud, G. M. Khan, H. S. Al-raweshidy, and S. Member, "Earliest-Deadline-Based Scheduling to Reduce Urban Traffic Congestion," IEEE Trans. Intell. Transp. Syst., vol. 15, no. 4, pp. 1510-1526, 2014, doi:10.1109/TITS.2014.2300693.

[19] Khushi, "Smart Control of Traffic Light System using Image Processing," in International Conference on Current Trends in Computer, Electrical, Electronics and Communication (CTCEEC), pp. 99-103, 2017, doi:10.1109/CTCEEC.2017.8454966.

[20] L. Qi, M. Zhou, and W. Luan, "A Two-level Traffic Light Control Strategy for Preventing Incident-Based Urban Traffic Congestion," IEEE Trans. Intell. Transp. Syst., vol. 19, no. 1, pp. 13-24, Jan. 2018, doi:10.1109/TITS.2016.2625324.

[21] R. F. Adebiyi, K. A. Abubilal, M. B. Mu'azu, and B. H. Adebiyi, "Development and Simulation of Adaptive Traffic Light Controller Using Artificial Bee Colony Algorithm," Int. J. Intell. Syst. Appl., vol. 8, pp. 68-74, 2018, doi: 10.5815/ijisa.2018.08.06.

[22] S. Mishra, D. Bhattacharya, and A. Gupta, "Congestion Adaptive Traffic Light Control and Notification Architecture Using Google Maps APIs,” Data, vol. 3, no. 4, 2018, doi:10.3390/data3040067.

[23] C. M. Silva, A. L. L. Aquino, and W. M. Jr, "Smart Traffic Light for Low Traffic Conditions A Solution for Improving the Drivers Safety," Mob. Netw. Appl., vol. 20, pp. 285-293, 2015, doi:10.1007/s11036-015-0571-x.

[24] C. Suthaputchakun and Z. Sun, "A Novel Traffic Light Scheduling Based on TLVC and Vehicles' Priority for Reducing Fuel Consumption and \$text $\{\mathrm{CO}\} 2$ S Emission," in IEEE Systems Journal, vol. 12, no. 2, pp. 12301238, June 2018, doi: 10.1109/JSYST.2015.2500587.

[25] R. Hawi, G. Okeyo, and M. Kimwele, "Smart Traffic Light Control using Fuzzy Logic and Wireless Sensor Network," in Computing Conference, 2017, pp. 450-460, doi:10.1109/SAI.2017.8252137.

[26] H. Chai, H. M. Zhang, D. Ghosal, and C. Chuah, "Dynamic traffic routing in a network with adaptive signal control," Transp. Res. Part C, vol. 85, pp. 64-85, 2017, doi:10.1016/j.trc.2017.08.017.

[27] U. Andayani, D. Arisandi, B. Siregar, M. F. Syahputra, and M. A. Muchtar, "Simulation of Dynamic Traffic Light Setting Using Adaptive Neuro-Fuzzy Inference System ( ANFIS ) Simulation of Dynamic Traffic Light Setting Using Adaptive Neuro-Fuzzy Inference System ( ANFIS ),” J. Phys. Conf. Ser., vol. 1235, 2019, doi:10.1088/1742$6596 / 1235 / 1 / 012058$

[28] F. Kurniawan, H. Sajati, and O. Dinaryanto, "Adaptive Traffic Controller Based On Pre-Timed System," TELKOMNIKA, vol. 14, no. 1, pp. 56-63, 2016, doi:10.12928/TELKOMNIKA.v14i1.2798.

[29] S. S. Mousavi, M. Schukat, and E. Howley, "Traffic light control using deep policy- gradient and value-functionbased reinforcement learning,” IET Intell. Transp. Syst., vol. 11, pp. 417-423, 2017, doi:10.1049/iet-its.2017.0153.

[30] A. Simdiankin, I. Uspensky, L. Belyu, and K. Ratnikov, "A method to assess congestion in various traffic directions A method to assess congestion in various traffic directions," Transp. Res. Procedia, vol. 36, pp. 725731, 2018, doi:10.1016/j.trpro.2018.12.099.

[31] W. Genders and S. Razavi, "Evaluating reinforcement learning state representations for adaptive traffic signal control," Procedia Comput. Sci., vol. 130, pp. 26-33, 2018, doi:10.1016/j.procs.2018.04.008.

[32] N. M. Sadiq and S. A. Adepoju, "Adaptive Traffic Control System using Modified Round Robin and Genetic Algorithm," i-manager's J. Digit. Signal Process., vol. 6, no. 2, pp. 17-24, 2018, doi:10.26634/jdp.6.2.15592.

[33] S. Roy and M. S. Rahman, "Emergency Vehicle Detection on Heavy Traffic Road from CCTV Footage Using Deep Convolutional Neural Network," 2019 Int. Conf. Electr. Comput. Commun. Eng., pp. 1-6, 2019, doi: 10.1109/ECACE.2019.8679295.

[34] I. Santos-gonzález, P. Caballero-gil, A. Rivero-garcía, and C. Caballero-gil, "Priority and collision avoidance system for traffic lights," Ad Hoc Networks, vol. 94, 2019, doi:10.1016/j.adhoc.2019.101931.

[35] M. Özkul, I. Capuni, and E. Domnori, "Context-Aware Intelligent Traffic Light Control through Secure Messaging," J. Adv. Transp., vol. 2018, 2018, doi:10.1155/2018/4251701.

[36] C. Miao, H. Liu, G. G. Zhu, and H. Chen, "Connectivity-based optimization of vehicle route and speed for improved fuel economy," Transp. Res. Part C, vol. 91, no. April, pp. 353-368, 2018, doi:10.1016/j.trc.2018.04.014.

[37] N. Taherkhani, S. Pierre, and S. Member, "Centralized and Localized Data Congestion Control Strategy for Vehicular Ad Hoc Networks Using a Machine Learning Clustering Algorithm,” IEEE Trans. Intell. Transp. Syst., vol. 17, no. 11, pp. 3275-3285, 2016, doi:10.1109/TITS.2016.2546555.

[38] X. Wen-juan and L. Jian-feng, "Application of Vision Sensing Technology in Urban Intelligent Traffic Control System,” 2018 4th Int. Conf. Comput. Technol. Appl, pp. 74-77, 2018, doi:10.1109/CATA.2018.8398659. 
[39] D. Hartanti, R. N. Aziza, and P. C. Siswipraptini, "Optimization of smart traffic lights to prevent traffic congestion using fuzzy logic,” TELKOMNIKA, vol. 17, no. 1, pp. 320-327, 2019, doi:10.12928/TELKOMNIKA.v17i1.10129.

[40] J. Ferrer, J. García-nieto, E. Alba, and F. Chicano, "Intelligent Testing of Traffic Light Programs : Validation in Smart Mobility Scenarios," Math. Probl. Eng, vol. 2016, 2016, doi:10.1155/2016/3871046.

[41] O. Younis, N. Moayeri, and S. Member, "Employing Cyber-Physical Systems : Dynamic Traffic Light Control at Road Intersections," IEEE Internet Things J., vol. 4, no. 6, pp. 2286-2296, 2017, doi:10.1109/JIOT.2017.2765243.

[42] Y. Celik and A. T. Karadeniz, "Intelligent Systems and Applications in Engineering Urban Traffic Optimization with Real Time Intelligence Intersection Traffic Light System,” Int. J. Intell. Syst. Appl. Eng., vol. 6, no. 3, pp. 214219, 2018, DOI: 10.18201/ijisae.2018644780.

[43] R. H. Goudar and H. N. Megha, "Next generation intelligent traffic management system and analysis for smart cities," in International Conference On Smart Technology for Smart Nation, 2017, pp. 999-1003.

[44] K. M. A. Yousef, A. Shatnawi, M. Latayfeh, K. M. Ahmad, A. Shatnawi, and M. Latayfeh, "Intelligent Tra ffic Light Scheduling Technique Using Calendar-Based History Information,” Futur. Gener. Comput. Syst, vol. 91, pp. 124-135, 2018, doi: 10.1016/j.future.2018.08.037.

[45] S. Kulkarni, "Intelligent Traffic Control System Implementation for Traffic Violation Control, Congestion Control and Stolen Vehicle Detection," Int. J. Recent Contrib. from Eng. Sci. IT, vol. 5, no. 2, pp. 57-71, 2017, DOI: 10.3991/ijes.v5i2.7230.

[46] K. Nellore and G. P. Hancke, "Traffic Management for Emergency Vehicle Priority Based on Visual Sensing," Sensors, vol. 16, no. 11, 2016, doi: 10.3390/s16111892.

[47] S. Kapoor, P. Gupta, P. Sharma, and P. N. Singh, "Intelligent Ambulance with Automatic Traffic Control," Int. Res. J. Eng. Technol, vol. 04, no. 04, pp. 1264-1266, 2017.

[48] S. Amir, M. S. Kamal, S. S. Khan, and K. M. A. Salam, "PLC Based Traffic Control System with Emergency Vehicle Detection and Management," in International Conference on Intelligent Computing,Instrumentation and Control Technologies (ICICICT), 2017, pp. 1467-1472, doi: 10.1109/ICICICT1.2017.8342786.

[49] A. Rego et al., "Software Defined Network-based Control System for an Efficient Traffic Management for Emergency Situations in Smart Cities," Futur. Gener. Comput. Syst, vol. 88, pp. 243-253, 2018, doi: 10.1016/j.future.2018.05.054

[50] B. J. Saradha, "Intelligent Traffic Signal Control System For Ambulance Using RFID And CLOUD," Int. Conf. Comput. Commun. Technol, pp. 90-96, 2017, doi: 10.1109/ICCCT2.2017.7972255.

[51] S. Antonov, "Smart traffic control system for ambulance," Advanced Aspects of Theoretical Electrical Engineering, Sofia'2016, pp. 95-98, 2017.

[52] T. Naik, R. Roopalakshmi, D. R. N, P. Jain, and B. H. Sowmya, "RFID-Based Smart Traffic Control Framework for Emergency Vehicles," 2018 Second Int. Conf. Inven. Commun. Comput. Technol., pp. 398-401, 2018.

[53] G. P. Id, T. C. Id, and A. Canale, "Smart Pedestrian Crossing Management at Traffic Light Junctions through a Fuzzy-Based Approach," Futur. Internet, vol. 10, no. 2, 2018, doi: 10.3390/fi10020015.

[54] H. J. Lee, R. Y. Kim and H. S. Son, "Evaluation of a Smart Traffic Light System with an IOT-based Connective Mechanism," International Information Institute (Tokyo). Information, vol. 20, no. 2, pp. 953-961, 2017. [Online]. Available: $\quad$ https://search.proquest.com/scholarly-journals/evaluation-smart-traffic-light-system-withiot/docview/2032343134/se-2?accountid=17242.

[55] R. Andronov and E. Leverents, "Calculation of vehicle delay at signal-controlled intersections with adaptive traffic control algorithm," MATEC Web Conf., vol. 143, 2018, DOI: 10.1051/matecconf/201714304008.

[56] K. An, Y. J. Jeong, S. Lee, and D. Seo, "Smart Crossing System using IoT," in IEEE International Conference on Consumer Electronics (ICCE), pp. 9-10, 2017.

\section{BIOGRAPHIES OF AUTHORS}

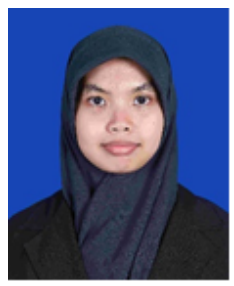

A'isya Nur Aulia Yusuf received the Bachelor degree in Information Technology from the Universitas Gadjah Mada 2018. She is a PMDSU scholarship awardee and a doctor candidate at the University of Indonesia. Her research interest are Machine Learning and IoT.

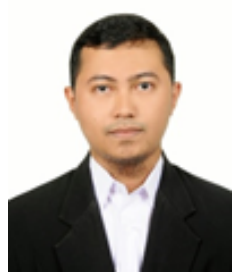

Ajib Setyo Arifin received the Bachelor in Electrical Engineering and Master's Degree from the Universitas Indonesia, in 2009 and 2011, respectively. He has got the $\mathrm{PhD}$ degree in Telecommunications in 2015 from the Keio University, Japan. He is an assistant professor at Universitas Indonesia. He is a head of telecommunication laboratory in Department of Electrical Engineering. His research areas include Wireless Sensor Networks, Wireless Communication, and signal processing for communication. He is a member of the IEEE. 
Fitri Yuli Zulkifli received all her degree in electrical engineering for Bachelor (1997) and PhD (cum laude) degrees, (2009) from Universitas Indonesia, while MSc degree in Telecommunication and Information Technology Department, University of Karlsruhe, Germany (2002). She received DAAD (Deutscher Akademischer Austauschdienst) scholarship to study her master degree in Germany. Her research interests are Antenna, Propagation, Microwave and in the field of Electromagnetic. She joined the Antenna Propagation and Microwave Research Group (AMRG) UI since 1997 and has become lecturer since 1998. She has published more than 200 papers in international/national journals and conference proceedings and has been involved in more than 40 granted researches. With all of here activities, in 2011 she was granted "Best Lecturer Award (Dosen Berprestasi)" from Universitas Indonesia and achieved 4th place "Best Lecturer Award" from the government of Republic Indonesia in the same year. Prof. Yuli is involved in many teamwork activities and also involved as organizing committee in many seminars and workshops. She has been the Secretary and Treasurer of IEEE joint chapter MTT/AP and in 2010 as Treasurer of the same joint chapter, then from 2011-2012 she has become the joint chapter chair. 2013-2016 she was the coordinator for technical activity in IEEE Indonesia section. In 2017-2018, she was the IEEE Indonesia Section Chair and in 2019-2020, she serves as committee member for R10 Conference and Technical Seminar and Conference Quality Management. Now she is the executive committee of joint chapter MTT/AP-S and also head of advisory board of IEEE Indonesia Section. 